\title{
Electrochemical Behavior of 1-Methyl-2-oxo-4,5-dichloro- quinolone in Aprotic Media at Glassy Carbon Electrode
}

\author{
RAMSWAROOP, ANUBHA SHARMA, K. K. JHANKAL and D. K. SHARMA* \\ Department of Chemistry, University of Rajasthan, Jaipur-302004, India \\ sharmadkuor@gmail.com
}

Received 24 December 2014 / Accepted 21 January 2015

\begin{abstract}
Many quinolones and substituted quinolones are well known for their biological activity. The redox characteristics of such biological substances may provide valuable information about the redox behavior in living systems. The present scenario involves electrochemical reduction of 1-methyl2-oxo-4,5-dichloroquinolone in aprotic solvent dimethylsulphoxide, carried out in basic medium which is irreversible and involves transfer of two electrons. A linear behavior of peak current versus square root of scan rate indicates that the electrochemical reduction processes are diffusion controlled.
\end{abstract}

Keywords: Quinolone, Cyclic voltammetry, Glassy carbon electrode, Diffusion-controlled, Irreversible

\section{Introduction}

Quinolones are very important compounds because of their pharmacological properties. Members of this family have wide applications in medicinal chemistry, being used as antimalarial, anti-inflammatory, anti-asthmatic, anti-bacterial, anti-hypertensive and tyrosine kinase inhibiting agents ${ }^{1-3}$. The structural core of quinolone has been generally synthesized by various conventional named reactions ${ }^{4-7}$. The quinolone ring systems are important structural units in naturally occurring alkaloids and synthetic analogues with interesting biological activities. Therefore, the development of new and efficient synthetic route for the preparation of their analogues is of importance in both synthetic organic chemistry and medicinal chemistry.

Electrochemical synthesis is much more economical eco-friendly, avoid massive chemical effluents. Such type of reactions is easy to control automatically as well as their reaction conditions are generally mild and effects of potential, $\mathrm{pH}$, buffer and solvent can be studied ${ }^{8-11}$. Electrochemical technique is a novel alternative method in organic synthesis, where one can synthesize the desired compound by oxidation or reduction of the substrate ${ }^{12-13}$.

The electrochemical reduction is one of the greener approaches because it is pollution free as electrons may be regarded as one of the reagents and it reduces the use of at least one hazardous chemical reagent ${ }^{14-15}$. As cyclic voltammetry is the most effective and versatile 
technique in the diagnosis of complex electrode mechanisms, in the present study this technique is employed to examine the electrochemical reduction of carbonyl group in BR buffer solution.

\section{Experimental}

All the reagents used were of analytical grade. 1-methyl-2-oxo-4,5-dichloroquinolone (Compound 1, Figure 1) was prepared from 1-methyl-2-oxo-4-hydroxy-5-chloroquinolone as shown in Scheme 1. Stock solution of compound 1 was prepared at a concentration of $1 \times 10^{-3} \mathrm{~mol} \mathrm{~L}^{-1}$ in DMSO. More diluted solutions were prepared from this solution in DMSO just prior to analysis. Britton-Robinson (BR) universal buffer of $\mathrm{pH} 12$ were prepared and used and as a supporting electrolyte.<smiles>Cn1c(=O)cc(O)c2c(Cl)cc(Cl)c(Cl)c21</smiles>

Scheme 1

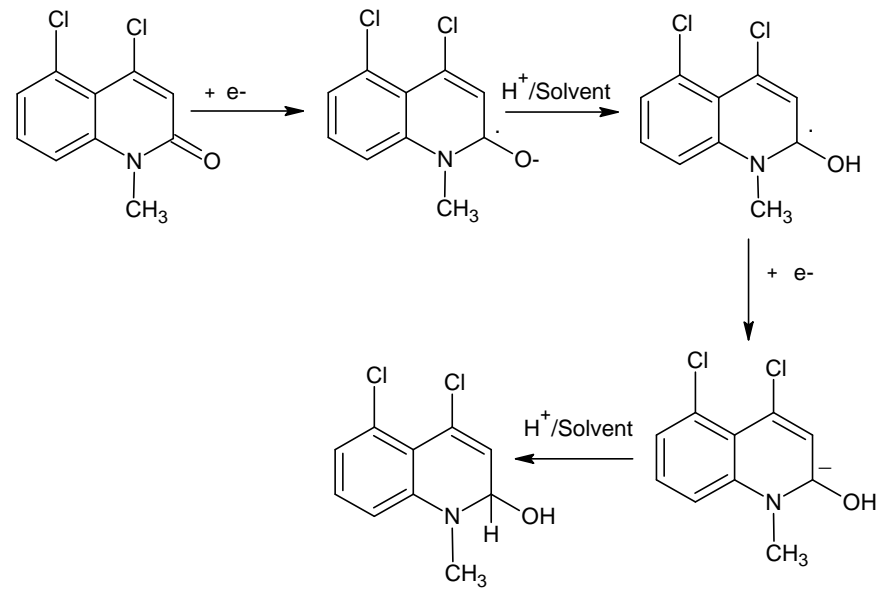

Scheme 2. Proposed Mechanism of Electrochemical Reduction

\section{Apparatus}

The voltammetric measurements were carried out on an electrochemical analyzer $(\mathrm{CH}$ instruments, USA, Model CHI 1230) equipped with a $10 \mathrm{~mL}$ single compartment three electrode glass cell. Glassy carbon electrode was used as the working electrode, a platinum wire as counter electrode and $\mathrm{Ag} / \mathrm{AgCl}$ electrode as reference electrode. All solutions used in the voltammetric system were deaerated with nitrogen for at least $15 \mathrm{~min}$ before executing the voltammetric experiments. All experiments were carried out at room temperature of $25 \pm 1{ }^{\circ} \mathrm{C}$. The GCE was polished using 0.3 micron aluminum oxide before each experiment.

\section{Results and Discussion}

The electrochemical behavior of 1-methyl-2-oxo-4,5-dichloroquinolone (Figure 1) at a GCE was studied by cyclic voltammetry in BR buffer of $\mathrm{pH}$ 12.0. The cyclic voltammogram obtained 
for $1 \times 10^{-6} \mathrm{~mol} \mathrm{~L}^{-1}$ solution (Figure 2) shows one distinct and well defined cathodic peak at $0.3 \mathrm{~V}$. No peak was observed on the reverse scan, indicating the irreversibility of electrode processes. The proposed mechanism involves single step electrochemical reduction which shows one cathodic peak in which carbonyl group is reduced directly to hydroxyl group by one two-electron charge transfer step (Scheme 2).<smiles>Cn1c(=O)cc(Cl)c2c(Cl)cccc21</smiles>

Figure 1. 1-Methyl-2-oxo-4,5-dichloroquinolone (Compound 1)

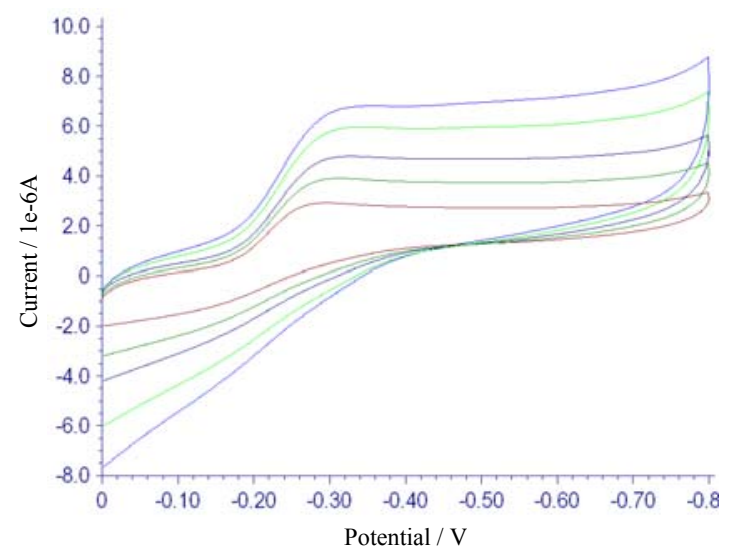

Figure 2. Cyclic voltammogram of $1 \times 10^{-6} \mathrm{~mol} \mathrm{~L}^{-1}$ compound 1 in Britton-Robinson buffer at different scan rates: (a) $25 \mathrm{mV}^{-1}$ (b) $50 \mathrm{mV}^{-1}$ (c) $75 \mathrm{mV}^{-1}$ (d) $100 \mathrm{mV}^{-1}$ (e) $125 \mathrm{mV}^{-1}$

\section{Scan rate dependence}

The study of effect of scan rate was made in order to postulate the mechanism and the feasibility of electrochemical reactions involved at GCE. It was observed in all cases, that the peak potential $\left(E_{\mathrm{pc}}\right)$ value shifts towards more negative side as the sweep rate $(v)$ increases. The electrochemical data obtained are summarized in Table 1. It is well evident from the results that the cathodic peak current $\left(i_{\mathrm{pc}}\right)$ increases with increasing sweep rate. The cathodic shift of peak potential with sweep rate, absence of anodic wave on reverse scan and fairly constant value of $i_{\mathrm{pc}} / v^{1 / 2}$ at higher scan rates confirm the reduction process to be diffusion controlled irreversible one.

Table 1. Effect of scan rate on cyclic voltammetric parameters

\begin{tabular}{cccccccc}
\hline $\begin{array}{c}\mathrm{SR}(\mathrm{v}) \\
\mathrm{mV} / \mathrm{s}\end{array}$ & $\begin{array}{c}i_{\mathrm{p}}, \\
\mu \mathrm{A}\end{array}$ & $\begin{array}{c}\log \mathrm{SR}, \\
\mathrm{mV} / \mathrm{sec}\end{array}$ & $\begin{array}{c}\mathrm{E}_{\mathrm{p}}, \\
\mathrm{V}\end{array}$ & $\begin{array}{c}\mathrm{E}_{\mathrm{p} / 2}, \\
\mathrm{~V}\end{array}$ & $\begin{array}{c}v^{1 / 2}, \\
\mathrm{mV} / \mathrm{sec}\end{array}$ & $\begin{array}{c}\log i_{\mathrm{p}}, \\
\mu \mathrm{A}\end{array}$ & $\alpha$ \\
\hline 25 & 1.999 & 1.397 & -0.267 & -0.1919 & 5.0 & 0.300 & 0.388 \\
50 & 2.496 & 1.698 & -0.302 & -0.1948 & 7.071 & 0.397 & 0.388 \\
75 & 2.983 & 1.875 & -0.326 & -0.1931 & 8.66 & 0.474 & 0.387 \\
100 & 3.611 & 2.0 & -0.351 & -0.1831 & 10 & 0.557 & 0.387 \\
125 & 4.012 & 2.096 & -0.368 & -0.1764 & 11.18 & 0.603 & 0.388 \\
\hline
\end{tabular}


The relationship between the peak current $\left(i_{\mathrm{pc}}\right)$ and the voltage scan rate $(v)$ was examined using the solution of concentration $1 \times 10^{-6} \mathrm{molL}^{-1}$ and recording cyclic voltammograms at different scan rates of 25, 50, 75, 100 and $125 \mathrm{mVs}^{-1}$ (Figure 2). The relationship between the cathodic peak current $i_{\mathrm{p}}(\mu \mathrm{A})$, the diffusion coefficient of the electro active species, $\mathrm{D}_{\mathrm{o}}\left(\mathrm{cm}^{2} \mathrm{~s}^{-1}\right)$ and the scan rate, $v\left(\mathrm{mVs}^{-1}\right)$, is described by the modified Randles-Sevcik equation $^{16}$ (Eq. 1)

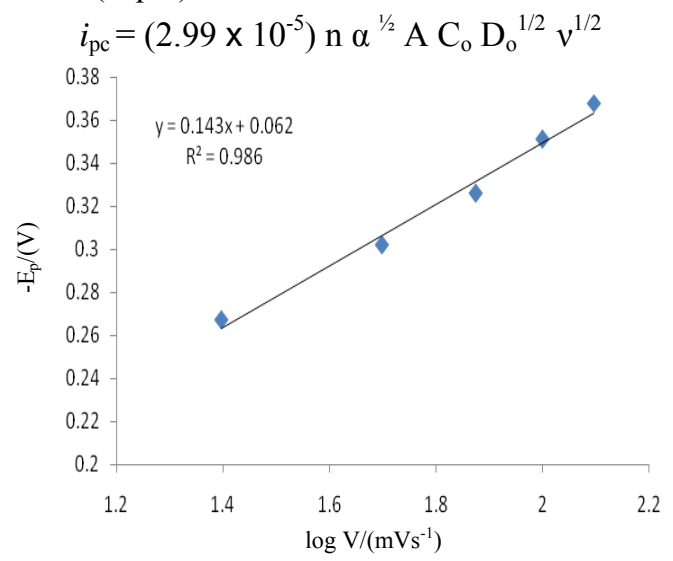

Figure 3. Plot of $-E_{\mathrm{p}} v s . \log v$ for the cyclic voltammogram of $1 \times 10^{-6} \mathrm{molL}^{-1}$ compound 1 in Britton-Robinson buffer of $\mathrm{pH} 12.0$

Where ' $n$ ' is the number of electrons exchanged in reduction, $\alpha$ is the transfer coefficient, $A$ is the apparent surface area of the electrode $\left(\mathrm{cm}^{2}\right)$ and $\mathrm{C}_{\mathrm{o}}$ is the concentration of the electro active species $\left(\right.$ moldm $\left.^{-3}\right)$. The transfer coefficient for an irreversible process can be calculated from following equation ${ }^{17}$ (Eq. 2)

$$
\left[\mathrm{E}_{\mathrm{pc}}-\mathrm{E}_{\mathrm{pc} / 2}\right]=47.7 / \alpha
$$

Where $E_{p c / 2}$ is the potential at which the current equals one half of the peak current. The height of the peak decreased with respective scans, its potential being not shifted. The relationship between the peak potential $\left(E_{\mathrm{pc}}\right)$ and the scan rate $(v)$ is expressed as (Eq.3),

$$
E_{\mathrm{pc}}=(2.303 \mathrm{RT} \alpha \mathrm{n} F) \log (\mathrm{RT} / \alpha \mathrm{n} F)-(2.303 \mathrm{RT} \alpha \mathrm{n} F) \log v
$$

In the present work, the plot of $-E_{\mathrm{pc}} v s . \log v$ was linear having a correlation coefficient of 0.995 (Figure 3) in $\mathrm{pH} 12.0$ and can be expressed as (Eq. 4),

$$
\left(E_{\mathrm{pc}}\right)=0.143 \log v+0.062(\mathrm{~V}) \text {, }
$$

According to the Randles - Sevcik equation in a linear diffusion controlled process $\left(i_{\mathrm{pc}}\right.$ verses $\left.v^{1 / 2}\right)$, for the adsorptive process $\left(\log i_{\mathrm{pc}}\right.$ verses $\left.v^{1 / 2}\right)$ and $\left(i_{\mathrm{pc}}\right.$ verses $\left.v\right)$. The peak currents of Compound I were plotted against the scan rate. The peak current $\left(i_{\mathrm{pc}}\right)$ increases linearly with the increasing scan rate. A linear relationship was observed between the reduction peak current verses the square root of the scan rate (Figure $4,5 \& 6$ ) with the significant correlation coefficient of 0.98 indicating thereby that the electrode process is diffusion-controlled between the scan rate of 25 and $125 \mathrm{mVs}^{-1}$ which is expressed by the equation,

$$
i_{\mathrm{pc}}(\mu \mathrm{A})=0.330 v^{1 / 2}\left(\mathrm{mVs}^{-1}\right)-0.245 ; \mathrm{r}^{2}=0.984
$$

The adsorption process was also identified by a plot of $\log i_{\mathrm{p}}$ versus $\log v$ (Figure 7) giving a straight line which can be expressed by the equation;

$$
\log i_{\mathrm{pc}}(\mu \mathrm{A})=0.436 \log v\left(\mathrm{mVs}^{-1}\right)+0.325 ; \mathrm{r}^{2}=0.979
$$




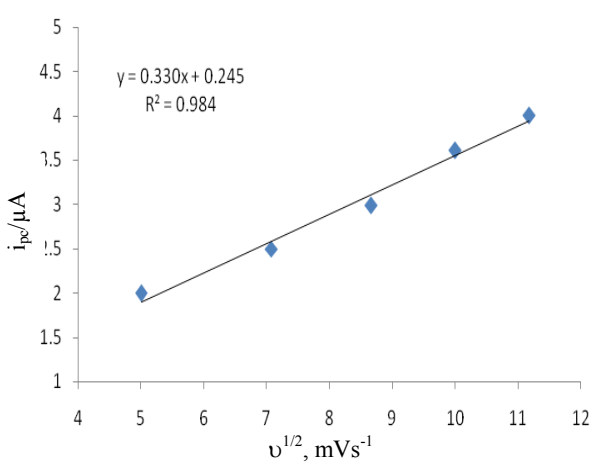

Figure 4. Plot of $i_{\mathrm{p}} v s . v^{1 / 2}$ for the cyclic voltammogram of $1 \times 10^{-6} \mathrm{molL}^{-1}$ compound 1 in Britton-Robinson buffer of $\mathrm{pH} 12.0$

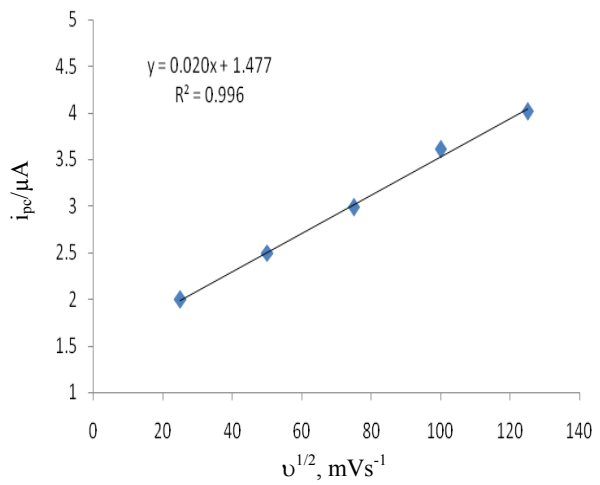

Figure 6. Plot of $i_{\mathrm{p}} v s$. $v$ for the cyclic voltammogram of $1 \times 10^{-6} \mathrm{molL}^{-1}$ compound 1 in Britton-Robinson buffer of $\mathrm{pH} 12.0$

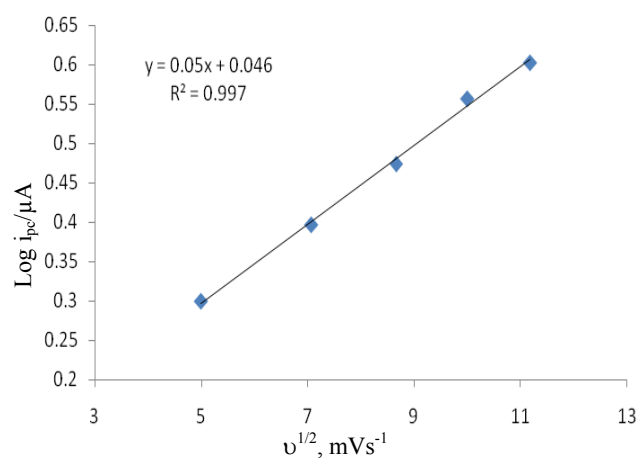

Figure 5. Plot of $\log i_{\mathrm{p}} v s . v^{1 / 2}$ for the cyclic voltammogram of $1 \times 10^{-6} \mathrm{molL}^{-1}$ compound 1 in Britton-Robinson buffer of $\mathrm{pH} 12.0$.

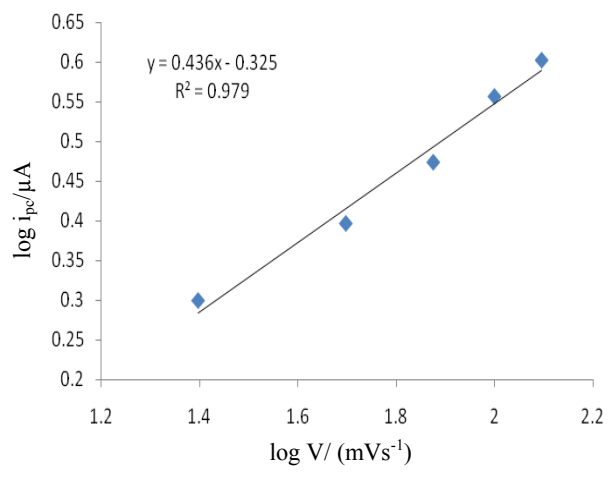

Figure 7. Plot of $\log i_{\mathrm{p}} v s . \log v$ for the cyclic voltammogram of $1 \times 10^{-6} \mathrm{molL}^{-1}$ compound 1 in Britton-Robinson buffer of pH 12.0.

The value of $\alpha$ as calculated from the slope of the plot between $E_{\mathrm{pc}} v s . \log v$ is 0.388 . In most of the irreversible cases $\alpha$ lies in the range of 0.30 to 0.70 . On the basis of above studies it is observed that the electrochemical reduction of Compound I at $\mathrm{pH} 12.0$ occurs in irreversible way and almost constant $\alpha$ values clearly indicates that the reaction is diffusion controlled.

\section{Effect of concentration}

Table 2 summarizes voltammetric data for Compound 1 in the highly basic medium. Concentration likewise affected the magnitude of the peak current. This was seen by obtaining scans of $1 \times 10^{-6}, 2.0 \times 10^{-6}, 3.0 \times 10^{-6}, 4.0 \times 10^{-6}$ and $5.0 \times 10^{-6} \mathrm{~mol} \mathrm{~L} \mathrm{~L}^{-1}$ of desired compound 1 using a scan rate of $50 \mathrm{mVs}^{-1}$ at $\mathrm{pH} 12.0$. The effect of concentration for compound 1 on the appearance of the cyclic voltammograms can be seen in Figure 8.

The Randles-Sevcik equation also indicates that $i_{\mathrm{pc}}$ is directly proportional to concentration. A plot of this equation $\left(i_{\mathrm{pc}} /\right.$ conc.) for compound 1 is shown in Figure 9 curve yields a straight line.

$$
i_{\mathrm{pc}}(\mu \mathrm{A})=0.384\left(10^{-6} \mathrm{M}\right)+1.530,\left(\mathrm{r}^{2}=0.992\right)
$$


Table 2. Effect of concentration on cyclic voltammetric parameters

\begin{tabular}{ccccc}
\hline Concentration, $\mathrm{mol} / \mathrm{L}$ & $i_{\mathrm{p}}, \mu \mathrm{A}$ & $\log i_{\mathrm{p}}, \mu \mathrm{A}$ & $\mathrm{E}_{\mathrm{p}}, \mathrm{V}$ & $\mathrm{E}_{\mathrm{p} / 2}, \mathrm{~V}$ \\
\hline $1.0 \times 10^{-6}$ & 1.941 & 0.2880 & -0.294 & -0.1919 \\
$2.0 \times 10^{-6}$ & 2.241 & 0.3504 & -0.325 & -0.1905 \\
$3.0 \times 10^{-6}$ & 2.720 & 0.4345 & -0.337 & -0.1934 \\
$4.0 \times 10^{-6}$ & 3.062 & 0.486 & -0.333 & -0.1791 \\
$5.0 \times 10^{-6}$ & 3.315 & 0.5204 & -0.350 & -0.1872 \\
\hline
\end{tabular}

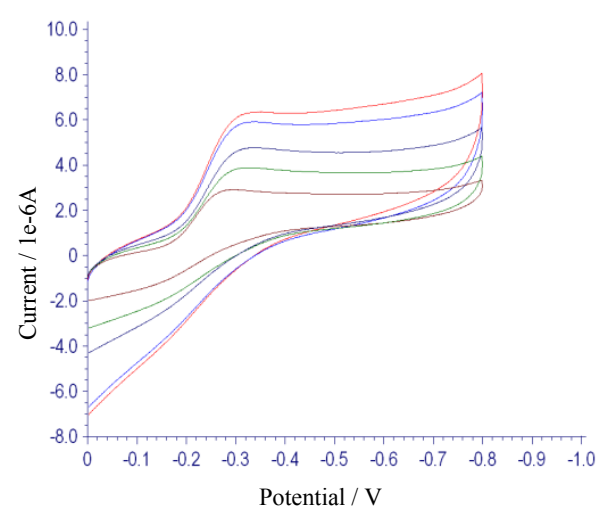

Figure 8. Cyclic voltammogram of compound I in Britton -Robinson buffer at scan rate $50 \mathrm{mVs}^{-1}$ in different concentrations: (a) $1 \times 10^{-6} \mathrm{molL}^{-1}$ (b) $2.0 \times 10^{-6} \mathrm{~mol} \mathrm{~L}^{-1}$ (c) $3.0 \times 10^{-6} \mathrm{~mol} \mathrm{~L}^{-1}$ (d) $4.0 \times 10^{-6} \mathrm{~mol} \mathrm{~L}^{-1}$ (e) $5.0 \times 10^{-6} \mathrm{~mol} \mathrm{~L}^{-1}$

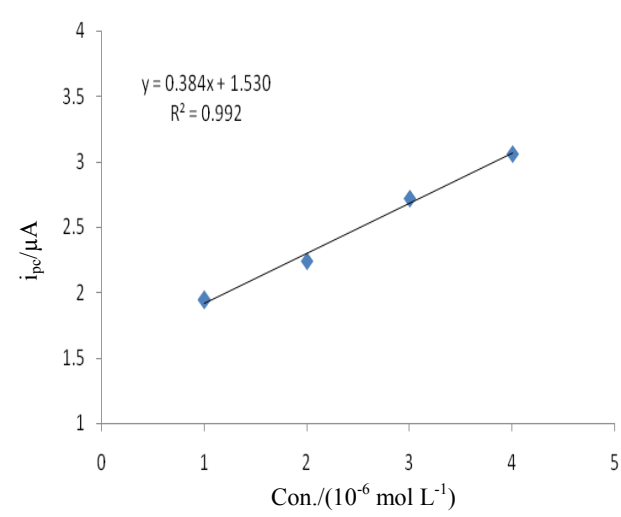

Figure 9. Plot of $i_{p} v s$. conc. for the cyclic voltammogram of compound I in BrittonRobinson buffer at scan rate $50 \mathrm{mVs}^{-1}$ in different concentrations: (a) $1 \times 10^{-6} \mathrm{~mol} \mathrm{~L}^{-1}$ (b) $2.0 \times 10^{-6} \mathrm{~mol} \mathrm{~L}^{-1}$ (c) $3.0 \times 10^{-6} \mathrm{~mol} \mathrm{~L}^{-1}$ (d) $4.0 \times 10^{-6} \mathrm{~mol} \mathrm{~L}^{-1}$ (e) $5.0 \times 10^{-6} \mathrm{~mol} \mathrm{~L}^{-1}$.

\section{Conclusion}

The investigations have demonstrated that examined 1-methyl-2-oxo-4,5-dichloroquinolone gave a well defined single irreversible peak at glassy carbon electrode in DMSO. The carbonyl group undergoes one step electrochemical reduction to form hydroxyl group via transfer of two electrons and shows one cathodic peak. The electrochemical process is diffusion controlled indicated by the linearity of peak current vs. square root of scan rate.

\section{Acknowledgement}

One of the authors (Ramswaroop) is thankful to C.S.I.R. New Delhi for providing financial assistance as Senior Research Fellowship (SRF).

\section{References}

1. Chen Y L, Fang K C, Sheu J Y, Hsu S L and Tzeng C C, J Med Chem., 2001, 44(14), 2374-2377; DOI:10.1021/jm0100335

2. Roma G, Braccio M D, Grossi G and Chia M, Eur J Med Chem., 2000, 35(11), 10211035; DOI:10.1016/S0223-5234(00)01175-2

3. Billker O, Lindo V, Panico M, Etiene A E, Paxton T, Dell A, Rogers M, Sinden R E and Morris H R, Nature, 1998, 392(6673), 289-292; DOI:10.1038/32667

4. Kouznetsov V V, Mendez L Y and Gomez C M, Curr Org Chem., 2005, 9, 141-161.

5. Combes A, Bull Chim Soc., 1888, 49, 89. 
6. Manske R H F, Chem Rev.,1942, 30(1), 113-144; DOI:10.1021/cr60095a006

7. Shraddha M P, Kinjal D P, Rajesh H V, Shyamali N P and Pate H D, RSC Adv., 2014, 4, 24463-24476; DOI: 10.1039/C4RA01814A

8. Mamta K and Sharma D K, J Korean Chem Soc., 2011, 55(1), 50-56; DOI:10.5012/jkcs.2011.55.1.050

9. Mamta K and Sharma D K, Croatica Chem Acta, 2011, 84(4), 455-460.

10. Sharma V K, Sharma D K and Gupta C M, Bull Electrochem., 1989, 5(5), 359-363.

11. Sharma D K, Sharma S, Mourya G L and Kumari M, J Indian Chem Soc., 2009, 86, 225-232.

12. Shano T, Electro-organic Chemistry as a New Tool in Organic Synthesis, Springer, New York, 1984, 145-147.

13. Shekhawat K S, Sharma H, Bhargav S K and Sharma D K, Chem Sci Trans., 2013, 2(4), 1334-1339; DOI:10.7598/cst2013.574

14. Zuman P, Barns B and Rovolova A, Discuss Faraday Soc., 1968, 45, 202-226; DOI:10.1039/DF9684500202

15. Schultz H P and Popp F D, Chem Rev., 1962, 62(1), 19-40; DOI:10.1021/cr60215a002

16. Nicholson R S, Anal Chem., 1965, 37(11), 1351-1355; DOI:10.1021/ac60230a016

17. Kolvada R and Kopanica M, Pure Appl Chem., 1989, 61(1), 97-112; DOI:10.1351/pac198961010097 